\title{
DEVELOPMENT OF A MULTI-SITE AND MULTI-DEVICE WEBGIS-BASED TOOL FOR TIDAL CURRENT ENERGY DEVELOPMENT
}

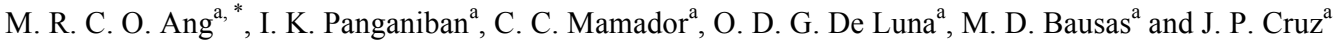 \\ ${ }^{a}$ Department of Geodetic Engineering, University of the Philippines Diliman, Quezon City, Philippines - moang@up.edu.ph, \\ (ian.panganiban, charmynemamador, oliver.dl, michaelbausas, joeytootlescruz21)@gmail.com
}

\author{
Commission VIII, WG VIII/5
}

KEY WORDS: Geographic Information Systems, Web-GIS, Site Suitability Analysis, Tidal Current Energy, Resource Assessment

\begin{abstract}
:
A multi-site, multi-device and multi-criteria decision support tool designed to support the development of tidal current energy in the Philippines was developed. Its platform is based on Geographic Information Systems (GIS) which allows for the collection, storage, processing, analyses and display of geospatial data. Combining GIS tools with open source web development applications, it becomes a webGIS-based marine spatial planning tool. To date, the webGIS-based tool displays output maps and graphs of power and energy density, site suitability and site-device analysis. It enables stakeholders and the public easy access to the results of tidal current energy resource assessments and site suitability analyses. Results of the initial development showed that it is a promising decision support tool for ocean renewable energy project developments.
\end{abstract}

\section{INTRODUCTION}

Ocean renewable energy (ORE) represents a significant resource for clean renewable electricity generation (Georgia Tech Research Corporation, ). Among the types of ORE are tidal current or tidal barrage, wave, ocean thermal gradient and salinity gradient. To date, only tidal barrage has reached commercial maturity. Ocean thermal energy conversion (OTEC) technologies are still very expensive and the lack of pilot sites with installed power systems harnessing this type of energy pulled away support from a number of investors worldwide. On the other hand, wave energy conversion (WEC) and tidal current energy, also known as tidal in-stream energy conversion (TISEC) systems have reached full-scale and are in the pre-commercial scales of maturity. When compared, tidal energy resource is considered more predictable and consistent than wave energy resource.

Tidal current energy is a form of energy that arises when streams of water flow between landmasses as a result of tidal height differences (Georgia Tech Research Corporation, ). Sites where available tidal current energy occurs in large quantities are those sites where the flow is constricted, resulting in higher current stream velocities. These properties are exhibited by channels and straits which can be found in many areas in the Philippines considering that the country is an archipelago surrounded by vast ocean.

Through the application of geographic information systems, this study aims to identify the Philippine's potential sites for conversion of tidal current energy and, at the same time, develop a webGIS-based marine spatial planning (MSP) tool for site analysis. Among the outputs of this study are resource (power and energy density) maps and suitability maps with considerations on physical, environmental and socio-economic factors. With these, potential sites for each TISEC device will be identified through site-device matching. This will help countries and organizations plan the use of their ocean resources (fishing, maritime and energy uses) with more efficiency and awareness (OES and EIA, ).

\section{FRAMEWORK FOR THE MARINE SPATIAL PLANNING TOOL DEVELOPMENT}

The development of the webGIS-based MSP tool has 4 components namely: resource assessment, site suitability analysis, site-device analysis, and MSP design and implementation. Fig. 1 shows the overall framework of the development.

\subsection{Resource Assessment}

The assessment of the tidal current energy resource potential involves the following processes: hydrodynamic modeling, model validation, optimization of parameters and conversion of the model results to power and energy density for mapping. The numerical hydrodynamic model Delft3D was utilized for modeling of tidal behavior of the Philippine seas. Results of the simulation were validated using observed data from tidal stations and in-situ measurements of tidal properties at different sites.

\subsection{Site Suitability Analysis}

To determine suitable sites for tidal current energy development from the potential areas identified during resource assessment, a GIS-based multi-criteria decision analysis (MCDA) was performed considering physical, environmental and socioeconomic factors as criteria [3]. Different criteria affecting the viability of development were identified and finalized by consultation with different stakeholders and experts. A site suitability analysis model was developed in a GIS platform where the different criteria will be given weights based on their importance and will be standardized and aggregated to come up with the site suitability map (Defne et al., 2011).

\subsection{Site-Device Analysis}

The total extractable power from a potential and suitable site can be determined by analyzing a site with reference to a particular 
device. Site-device matching was done to identify devices suitable for deployment for a particular site. More than 140 TISEC devices were identified including those under conceptual design, laboratory scale, sea scale and pre-commercial scale. This long list was shortlisted to about 25 based on the assessment of the International Renewable Energy Agency (IRENA) as actively being developed by their manufacturers (Mofor et al., 2014 and Kempener et al., 2014).

There are several criteria that can be used as reference in decision-making for site-device matching as suggested by (Abundo, ). These are: the devices' technical (energy yield, capacity and availability factors), economic (relative levelized cost of energy) and environmental (significant impact factor) characteristics. The suitability of each device can be determined by assigning suitability scores based on these criteria. For this study, the criteria used were annual energy yield, capacity factor and availability factor.

\subsection{MSP Design and Implementation}

Due to improved connectivity and processing power, internet applications became more powerful and sophisticated especially in the realm of Geographic Information Systems. Geographic Information System is a tool in managing, manipulating, and visualizing spatial data. It can execute queries and processes such as overlays, feature identification and others (Adnan, 2010). The increase in internet speeds helped in extending an ordinary desktop GIS application to one that is connected over a network, WebGIS (Rani, 2009 and Harper, 2006).

WebGIS is simply a GIS over the internet. It is used to solve problems like determining food and vacation hotspots, shortest routes to more complicated ones like modelling traffic flow or placement of relief in disasters (Gkatzoflias, 2012). One advantage of using WebGIS from the traditional desktop GIS is portability and accessibility because it does not require high end hardware and resources. Since it is accessed through the web, the audience or clients who can use the tool can be anyone and it can be used by a number of users simultaneously (Willmes, 2010).

In developing the MSP tool, the back-end and front-end developments were simultaneously made. Fig. 2 shows the development workflow. Establishing the back-end of the tool, Django, a Python web framework was used. The primary technology used for storing and managing spatial data was the latest version of Geoserver. Multiple instances of Geoserver were deployed to accommodate continuous data requests. To perform raster manipulation, Geospatial Data Abstraction Library was added to the application (Fig. 3).

User interface and experience design were the main points in front-end development. Using HTML and CSS, the application's interface was created. The website was designed to accommodate varying screen resolutions making it more accessible and device compatible.

With the use of JavaScript and jQuery, element behaviors were managed. The map functions and capabilities were scripted using different JavaScript plugins. Among the most essential of these is the JS map library, Leaflet, which provides the basic map controls. For visualization, Data-Driven Documents or D3.js was used.

Through W3C, World Wide Web Consortium, and OGC, Open Geospatial Consortium, compliant technologies mentioned, end- users can perform spatial functions such as raster data access, manipulation and visualization.

\section{CURRENT PROTOTYPE DEVELOPMENT}

The webGIS-based MSP tool, called PhilSHORE or Philippine Sites for Harnessing Ocean Renewable Energy, will enable stakeholders and the public access the results of the analyses and assessments, particularly, outputs from the hydrodynamic modelling, site-device matching and site-suitability analysis. The development of the tool is composed of modules created for the backend, frontend and specific functions of the applications. The backend deals with server and data management while the frontend deals with the design and layout of the applications.

The current development has five sections. They are: (1) the Home Section, landing page which displays the project logo and "Proceed to Map" button; (2) the Map Section, which presents a base map with corresponding functions such as pan, zoom, select, identify, etc.; (3) the Help Section, which shows the manual and short description of each tool; (4) the About Section, which displays a description of the project and the team. It also shows the different logos of the partner organizations and institutions in the development; (5) the Contact Section, which shows the contact information of the developers.

The website features were implemented containing the following functions / tools:

- Layer Overlay - The user will be able to control which layers are visible. The layers have three general categories; base map source, site suitability, and device layers. Fig. 4 shows the layer overlay function diagram.

- Base map layer - the client/user can choose from different base map providers such as MapQuest, OpenGeo, and Bing maps. The client/user can only select one base map.

- Site Suitability layer - the client/user can choose from different site suitability layers which are the following: environmental score, accessibility, and power density. The client/user can activate all the layers in the site suitability layer.

- Device Layer - this layer will have four additional categories namely: horizontal, vertical, oscillating and others.

- $\quad$ Legend -This will show the legend of the activated layers. The user can also turn off the legend of the active layer.

- Query - The query tool will have two other components, the site suitability calculator and the device to site identification tool.

- $\quad$ Map Tools - This will contain the other tools which can be used by the client like point identification, zoom to extent, and print map.

- Map Settings - The client can customize the visibility of the elements (zoom buttons, overview map, and zoom slider and selection navigation) on the map. Screenshots of the prototype in shown in Fig. 5. 


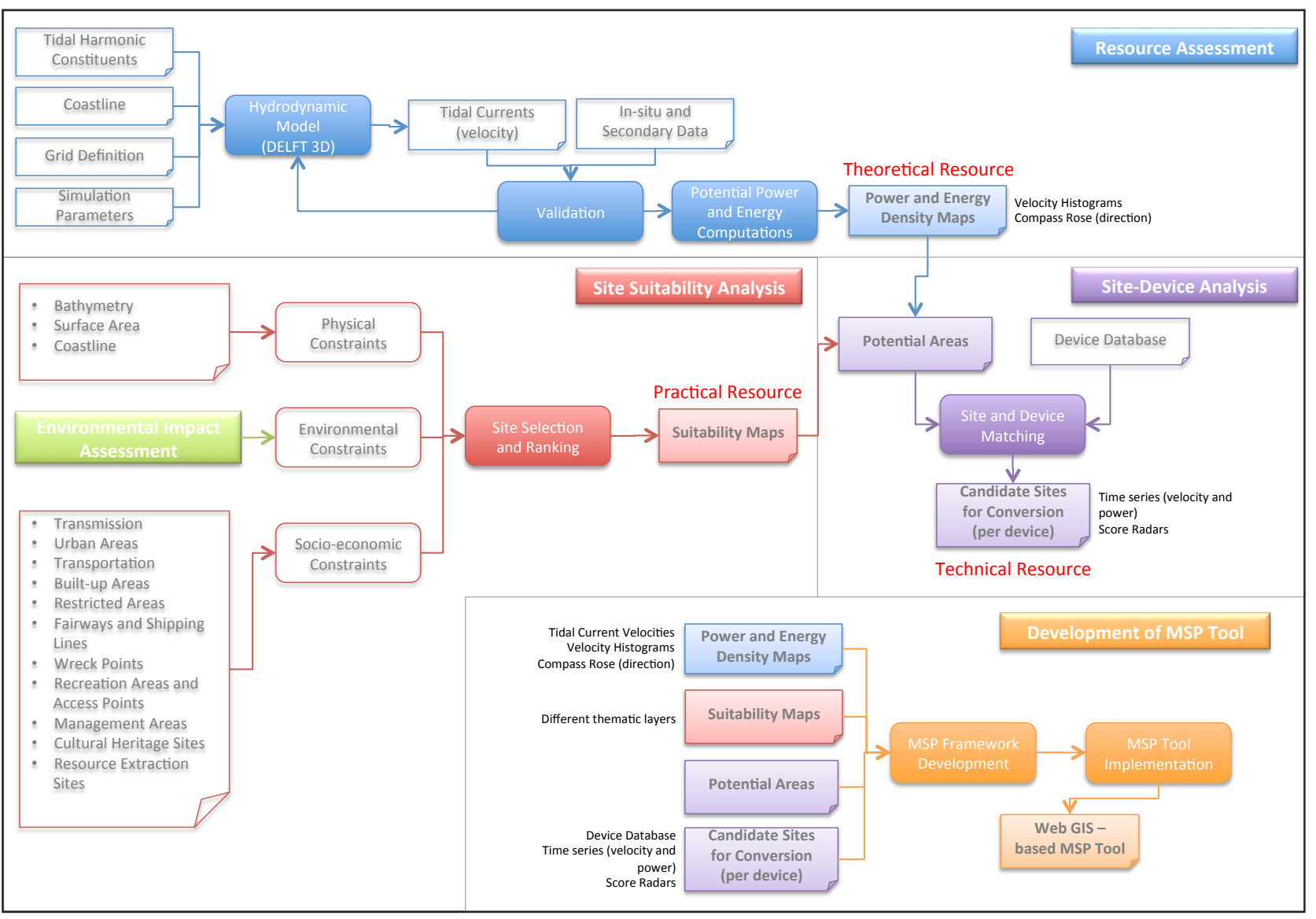

Figure 1. Conceptual framework for the development of the MSP tool.

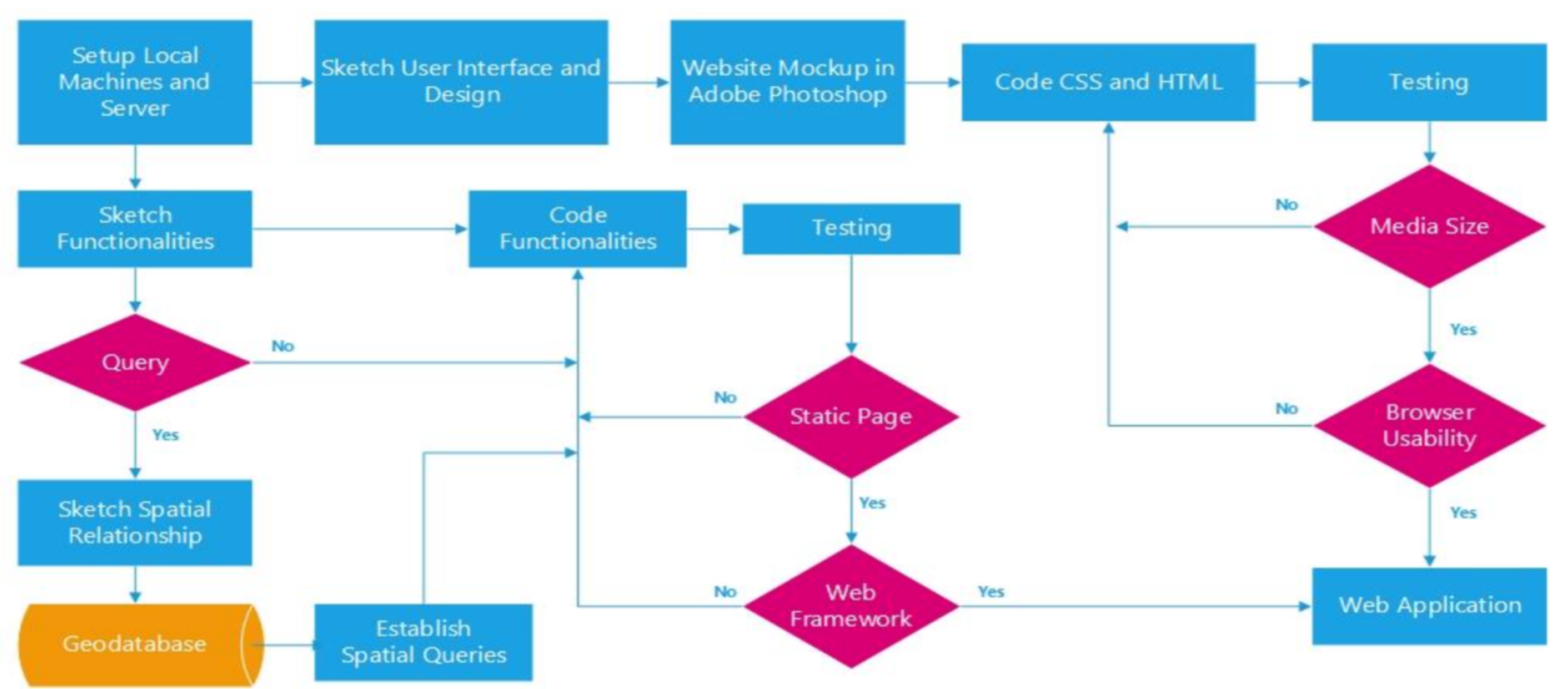

Figure 2. Backend and Frontend development workflow. 


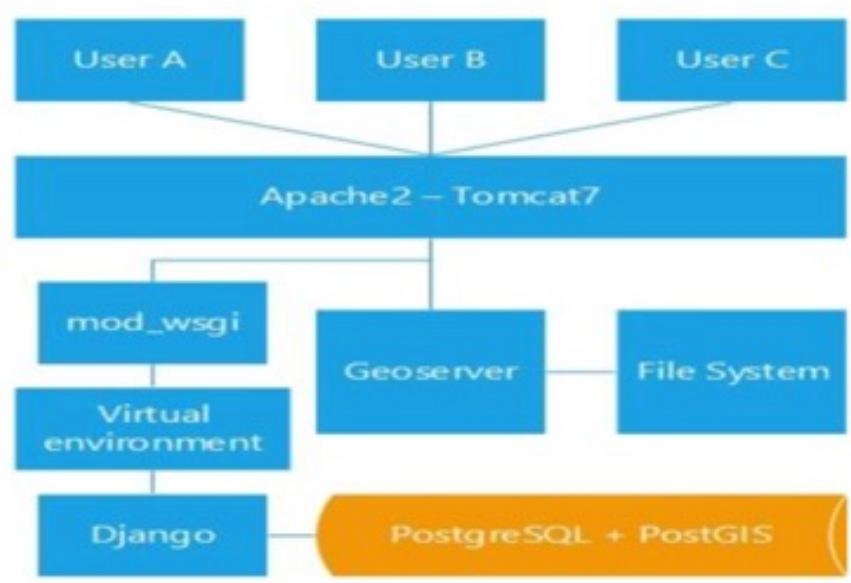

Figure 3. Application structure.

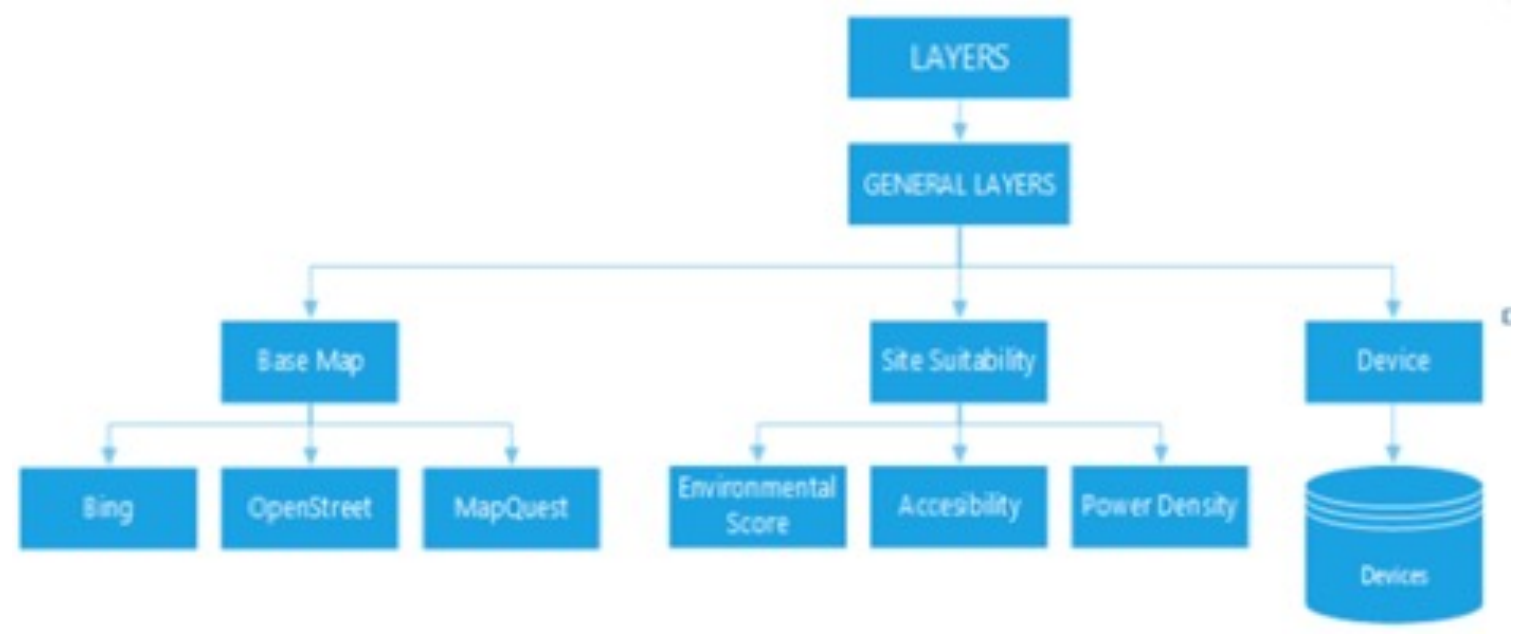

Figure 4. Layer overlay function diagram.

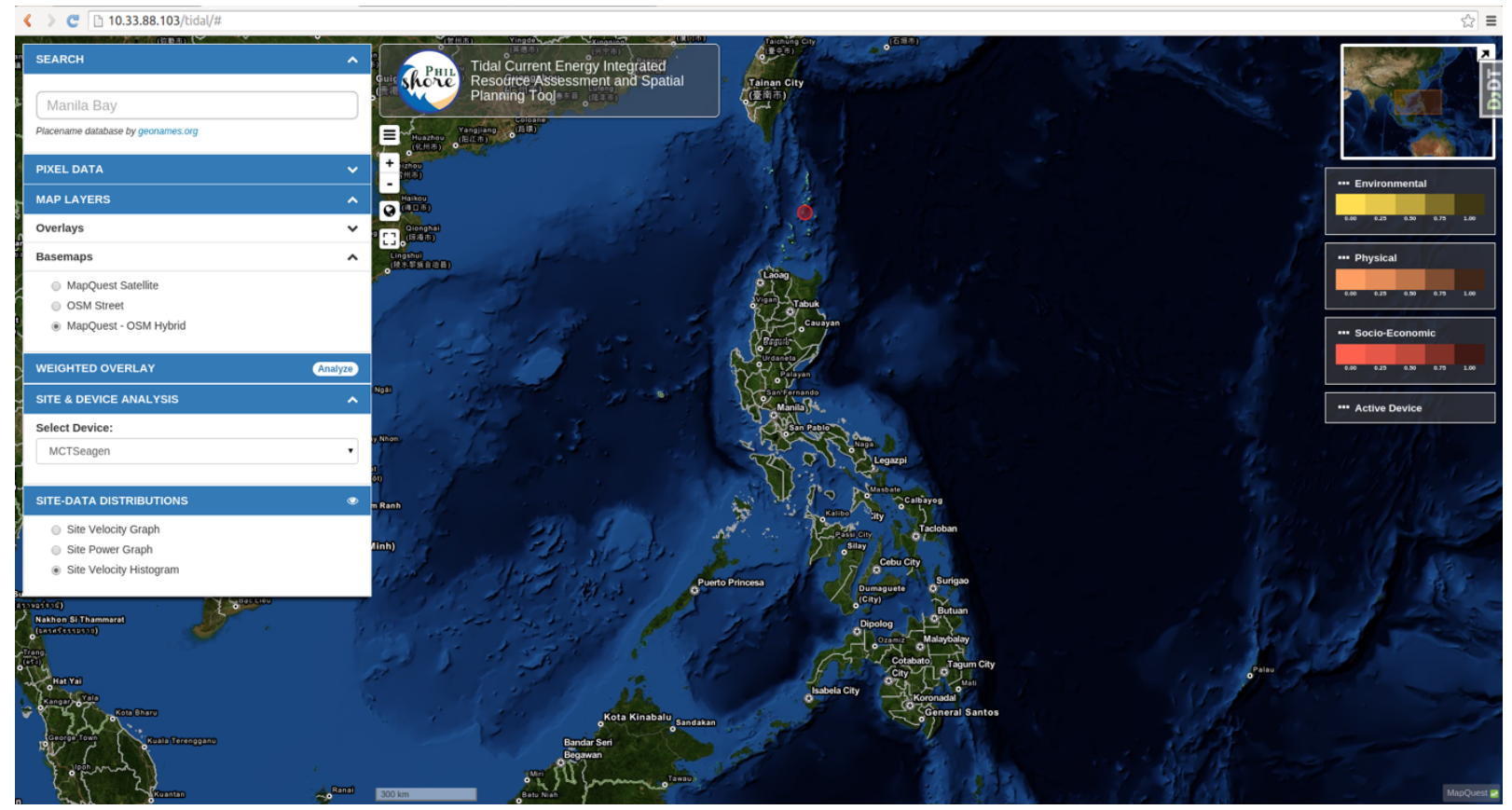

Figure 5. Screenshot of the marine spatial planning (MSP) tool prototype (a) basemap; (b) layer overlay; (c) site power map. 

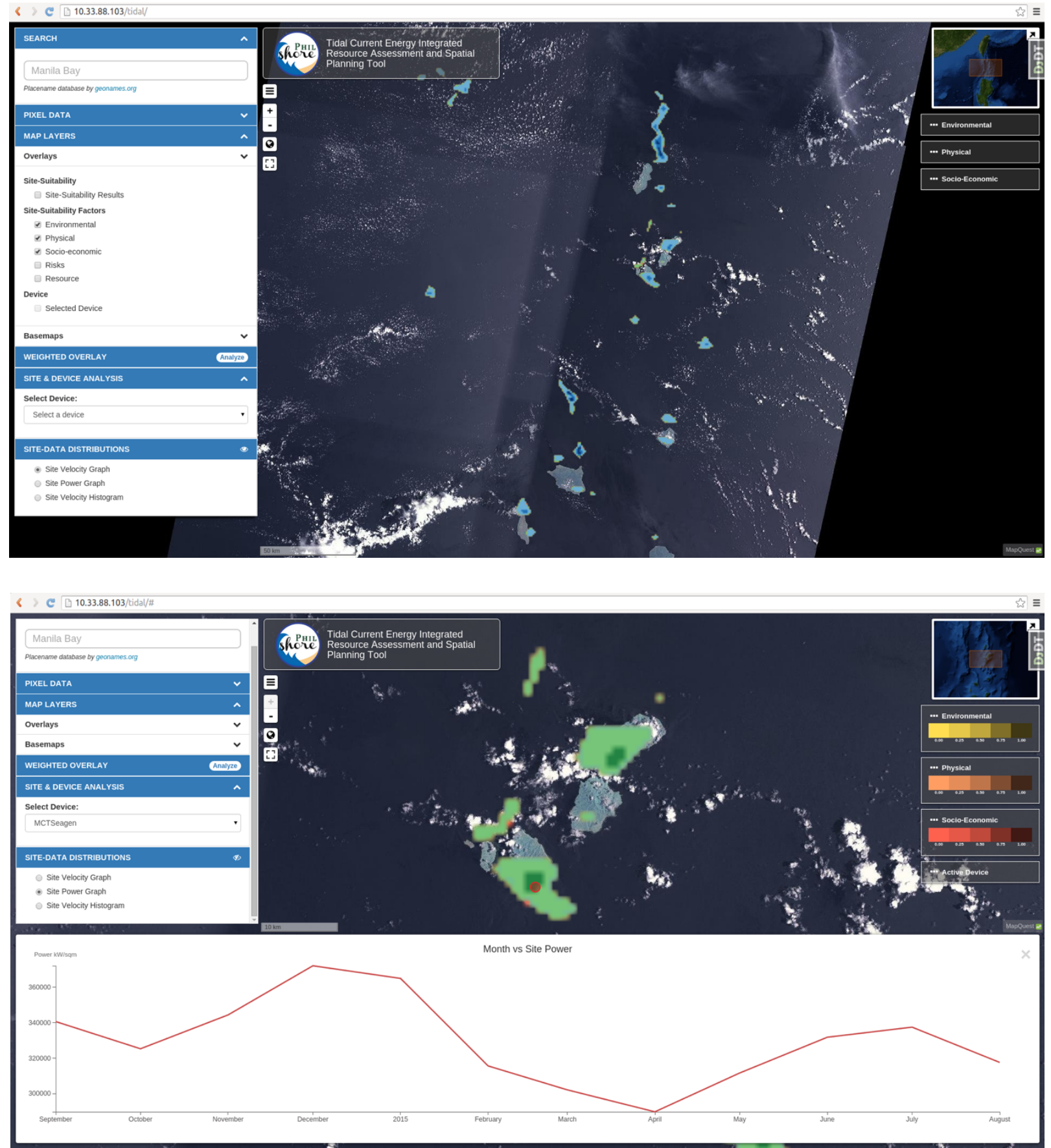

\section{CONCLUSION}

Developing a webGIS-based tool such as PhilSHORE addresses the need for fast, easy access to multi-layered GIS data and tools for the purposes of ORE planning.It enable stakeholders and the public access to the results of the analyses and assessments, particularly, outputs from the hydrodynamic modelling, sitedevice matching and site-suitability analysis.It offers advantages to ORE project developers and investors, such as quicker result generation, in-depth analysis, convenience, and cost reduction. Results of the initial development shows that PhilSHORE is a promising decision support tool for ORE project developments.

\section{ACKNOWLEDGEMENTS (OPTIONAL)}

The authors would like to acknowledge the Philippine Council for Industry, Energy and Emerging Technology Research and Development of the Department of Science and Technology (PCIEERD-DOST) for the financial support given for this research. Sincerest gratitude is also extended to Dr. Laura David, Dr. Louie Danao, Ms. Ma. Elena C. Ignacio, Mr. Justine Dela Cruz and Ms. Marianne Catanyag for their invaluable support and assistance in the conduct of this research. 


\section{REFERENCES}

Abundo, M.L.S., Integrated Tidal Resource Investigation, Device and Energy Tool (TRIDEnT) for Multi-Site, Multi-Device Evaluation of Tidal In-stream Energy, unpublished.

Adnan, L. P., 201. Developing Efficient Web-based GIS Applications, UCL Centre for Advanced Spatial Analysis, vol. 153, p. 15 .

Defne, Z., Haas, K.A., and Fritz, H. M., 2011. GIS based multicriteria assessment of tidal stream power potential: A case study for Georgia, USA, Renewable and Sustainable Energy Reviews, vol. 15 , pp. $2310-2321$.

Georgia Tech Research Corporation, Assessment of energy production potential from tidal streams in the United States - Final Project Report," unpublished.

Gkatzoflias, S. Z., 2012. Development of a web GIS application for emissions inventory spatial, Science Direct, p. 13.

Harper, E., 2006. Open-Source Technologies in Web-Based GIS and Mapping.

Kempener, R., and Neumann F., 2014. Tidal Energy: Technology Brief, Abu Dhabi.

Mofor, L., Goldsmith J., and Jones, F., 2014. OCEAN ENERGY: Technology Readiness, Patents, Deployment Status and Outlook, Abu Dhabi, UAE.

Ocean Energy Systems (OES), Internatioanl Energy Agency (IEA) “2011 Annual Report,” online. (Accessed: August 26, 2013).

Rani, K.M.U., 2009. Web 2.0 Mapping Mashup Applications for Academic Universities-Comparative Case Study (Secure Google Maps API versus Microsoft Virtual Earth API), International Journal of Information Technology and Knowledge Management, p. 8. 